\title{
Acta
Biochimica
Polonica
}

Vol. 52 No. 1/2005

\section{Co-inoculation with two non-infectious cDNA copies of potato spindle tuber viroid (PSTVd) leads to the appearance of novel fully infectious variants}

\author{
Wojciech Podstolski ${ }^{\bowtie}$, Anna Góra-Sochacka and Włodzimierz Zagórski
}

Institute of Biochemistry and Biophysics, Polish Academy of Sciences, Warszawa, Poland

Received: 26 July, 2004; accepted: 06 January, 2005

Key words: circular RNA, non-coding RNA, PSTVd, recombination, viroid

\begin{abstract}
Potato spindle tuber viroid (PSTVd) is one of the smallest (about $360 \mathrm{nt}$ ) infectious plant agents. It is composed of a single-stranded circular non-coding RNA molecule. In the course of previous passage experiments with two intermediate PSTVd variants I2 and I4, three non-infectious clones (I2-50, I4-37 and I4 VI-17) were found. When inoculated separately as cDNAs on tomato "Rutgers" test plants these variants did not induce any visible disease symptoms and did not produce progeny. The presence of such non-infectious variants raises several questions about their origin and biology and to answer them, mixed co-infections with cDNA copies of two non-infectious variants (I2-50, I4-37) were performed. PSTVd infection was observed in seven out of 30 inoculated plants. The progeny isolated from three separate plants contained novel variants, together with the parental I2 and I4 sequences. It is conceivable that the appearance of repaired PSTVd molecules, clearly capable of cell-to-cell movement leading to the systemic infection, results from recombination events. An analysis of the recombinant molecules and comparison with databases identified the specific sites responsible for the restricted infectivity of the I2-50 and I4-37 PSTVd variants. In parallel experiments in which $(+)$ strand PSTVd infectious transcripts were used, no recombinants were observed, and the original I2-50 and I4-37 non-infectious sequences were not detected in the progeny.
\end{abstract}

\footnotetext{
This research was partially supported by funds from the Polish-French Center for Biotechnology.

"The cDNA sequences of new PSTVd variants identified in the experiment are deposited in the NCBI database under the following numbers: AY492075 (S1), AY492076 (S2), AY492077 (S3), AY492078 (S4), AY492079 (S5), AY492080 (S6), AY492081 (S7), AY492082 (S8), AY492083 (S9), AY492084 (S10).

${ }^{\otimes}$ Correspondence to: Wojciech Podstolski, Institute of Biochemistry and Biophysics, Polish Academy of Sciences, A. Pawińskiego 5A, 02-106 Warszawa, Poland; tel.: (48 22) 592 3408, or (48 22) 6727072 + 3408; fax: (48 22) 658 4636; e-mail: wojciechp@ibb.waw.pl

Abbreviations: C, central; P, pathogenicity; PSTVd, potato spindle tuber viroid; TR, terminal right; V, variable.
} 
Potato spindle tube viroid (PSTVd), one of the smallest (about $360 \mathrm{nt}$ ) infectious plant agents, is a circular single-stranded RNA molecule (Diener, 1971). As other RNA genomes, it presents a high degree of variability due to naturally occurring mutations (Gandia \& Duran-Vila, 2004; Gomez et al., 1999; Naraghi-Arani et al., 2001; Pellerin et al., 2004; Schneider \& Roossinck, 2001).

Based on the symptoms it causes in tomato test plants, each sequence variant can fall into one of three separate categories, either severe, intermediate or mild (Fernow, 1967).

The relationships between sequence and function of these categories were studied by de novo creation of progeny populations from individual parental variants (Góra et al., 1997). In the course of such experiments with the parental I2 and I4 PSTVd variants that caused intermediate symptoms, three non-infectious clones (I2-50, I4-37, I4 VI-17) were found among a wide spectrum of progeny molecules. When test plants were inoculated with viroid cDNA of these three novel variants cloned in pUC9 plasmid, they showed no visible disease symptoms and no accumulation of viroid RNA. Therefore the mutants were considered non-infectious.

The presence of non-infectious mutants in a population of viable variants is a puzzling observation. One would expect these lethal bona fidae mutants unable to replicate on their own to be eliminated from the progeny viroid population. Yet the repeated demonstration of the presence of such variants amongst the progeny of productive infections refutes this assumption.

Formally, it is possible that the discovered non-infectious PSTVd variants carry mutations that impede either replication inside the host or cell-to-cell transport. In the latter case replication could be limited to the site of primary infection, remaining difficult to be detected by phenotype or by hybridization. Restrictions of this kind would prevent such variants from spreading and detectable systemic infection of the host plants. Alterna- tively, the replication and/or spread of non-infectious mutants could be supported in trans by other PSTVd variants present in the population, fulfilling a helper function. To distinguish between these possibilities, co-infection studies were performed using PSTVd cDNA clones of defined sequences (full-length PSTVd cDNA cloned in pUC9 vector) in which the potential for complementation between two different PSTVd mutants was tested.

Our experiments show that mixed infection with two non-infectious PSTVd variants is results in the appearance of recombinant progeny with restored infectivity accompanied by disappearance of the non-infectious I2-50 and I4-37 variants from the progeny. These observations support the model of non-infectious variants confined only to cells in which they were formed or to the sites of primary infection, and argues against hypothetical helper functions between mutated PSTVd genomes.

\section{MATERIAL AND METHODS}

PSTVd sequence variants. The sequence variants I2-50 and I4-37 were detected and cloned during plant passages of the I2 and I4 PSTVd variants (Góra-Sochacka et al., 1997). PSTVd cDNA was cloned into the pUC9 plasmid in the $(+)$ orientation. The parental I2 and I4 variants were detected and cloned from field isolates (Góra et al., 1994). I2 is identical to the previously described PSTVd type sequence PSTVd-DI (Gross et al., 1978).

Transcript synthesis. I2-50 and I4-37 cDNA copies were re-cloned from pUC9 to pGEM-3Z vector, between EcoRI and HindIII restriction sites, under control of SP6 promoter. Positive strand transcripts were obtained by in vitro transcription using SP6 polymerase (Promega) in standard conditions according to manufacturer's instructions.

Infectivity assays. Tomato "Rutgers" plant seedlings at two leaf stage were inoculated with $2 \mu \mathrm{g}$ of a recombinant pUC9 plasmid (2 
$\mu \mathrm{g}$ suspended in $20 \mu \mathrm{l}$ of sterile $\mathrm{H}_{2} \mathrm{O}$ ) (Candresse et al., 1990) carrying a monomeric full-length cDNA copy of the I2-50 or I4-37 PSTVd variant. The inoculation was performed by rubbing the plasmid suspension into carborundum dusted leaves. Inoculation with cDNA ensures that a PSTVd clone of precisely defined sequence is introduced into the test plants. In double inoculation assays the mixture (1:1) contained $2 \mu \mathrm{g}$ of each recombinant plasmid. Transcript inoculation experiments were performed in the same manner, with each plant inoculated with $1 \mu \mathrm{g}$ of full-length $(+)$ strand PSTVd transcripts. Plants were cultivated for five weeks in greenhouse conditions appropriate for the development of viroid infection. Samples (5 $\mathrm{g}$ of top leaves) were ground in a buffer containing $0.2 \mathrm{M} \mathrm{K}_{2} \mathrm{HPO}_{4}, 0.1 \%$ Triton X-100, $5 \mathrm{mM}$ dithiothreitol (DTT) and $10 \mathrm{mM}$ DIECA (sodium diethyldithiocarbamate), and used for RNA extraction and dot blot hybridization (DIG non-radioactive method, Roche) as described previously (Wełnicki \& Hiruki, 1993).

RNA extraction, cDNA synthesis, cloning and sequencing. Total low molecular weight RNA was prepared and the full-length cDNA was synthesized by RT-PCR using Pfu DNA polymerase and cloned into the pUC9 vector as described before (Góra et al., 1994). Sequencing of the cloned inserts was performed on an ABI sequencing system using a fluorescent primer kit. The sequences were aligned and compared using the MegAlign program from the DNAStar packet (DNASTAR Inc., Lasergene).

\section{RESULTS AND DISCUSSION}

\section{Inoculations with cDNA}

Twenty tomato "Rutgers" test plants were inoculated with homogenous cDNA of I2-50 or I4-37 variants (as determined by prior sequencing); each variant was tested on 10 separate plants. Another thirty plants were co-in- oculated with a cDNA (1:1) mixture of the I2-50 and I4-37 PSTVd variants.

As expected from previous trials (Góra et al., 1997), none of the twenty plants inoculated with either cDNA variant (I2-50 or I4-37) alone showed any visible symptoms. RNA extracts from top leaves emerging after inoculation were used for dot-blot hybridization to test for systemic viroid spread. Therefore the negative results obtained demonstrate a lack of viroid spread. However, none of the thirty plants co-inoculated with the mixture of the I2-50 and I4-37 variants showed any visible disease symptoms, but seven of them contained PSTVd. This shows that co-infection had led to replication and spread of PSTVd without the appearance of detectable symptoms.

Three dot-blot positive plants were selected for further sequence analyses of viroid progeny. Ten clones from each plant were sequenced, and a total of 10 different PSTVd variants were found (Table 1). Strikingly, the original I2-50 and I4-37 sequences were not detected among the progeny. The population represented a mixture of novel PSTVd variants not previously described.

\section{Inoculations with (+) strand PSTVd transcripts}

Plants were inoculated with transcripts of non-infectious clones. Two batches of 15 plants each were separately inoculated with (+) strand transcripts of I2-50 and I4-37 PSTVd variants. Another 30 plants were inoculated with a 1:1 mixture of these transcripts. None of the plants showed any disease symptoms, although dot-blot hybridization revealed that infected plants were present in each group: $3 / 15$ plants among the I2-50 inoculated plants, 2/15 among the I4-37 inoculated plants and 10/30 in the co-infected group. This result shows that in contrast to viroid cDNA the transcripts used for inoculation were infectious. 
Table 1. PSTVd parental and progeny variants accumulating in tomato 'Rutgers' plants co-inoculated with the full-length cDNAs of two non-infectious PSTVd clones, I2-50 and I4-37.

\begin{tabular}{llllllll}
\hline \multirow{2}{*}{$\begin{array}{l}\text { Sequence variant found in } \\
\text { the progeny }\end{array}$} & $\begin{array}{l}\text { Number of vari- } \\
\text { ants with a given } \\
\text { sequence }\end{array}$ & \multicolumn{7}{l}{$\begin{array}{l}118 \\
\text { (C/V) }\end{array}$} & $\begin{array}{l}164 \\
\text { (TR) }\end{array}$ & $\begin{array}{l}173 \\
\text { (TR) }\end{array}$ & $\begin{array}{l}197 \\
\text { (TR) }\end{array}$ & $\begin{array}{l}310 \\
\text { (P) }\end{array}$ & Other \\
\hline S1 & 2 & $5 \mathrm{~A}$ & $\mathrm{U}$ & $\mathrm{A}$ & $\mathrm{G}$ & $\mathrm{A}$ & \\
S2 & 1 & $5 \mathrm{~A}$ & $\mathrm{U}$ & $\mathrm{A}$ & $\mathrm{G}$ & $\mathrm{A}$ & $167 \mathrm{C} / \mathrm{U}$ (TR) \\
S3 & 5 & $5 \mathrm{~A}$ & $\mathrm{U}$ & $\mathrm{A}$ & $\mathrm{A}$ & $\mathrm{A}$ & \\
S4 (I4) & 7 & $5 \mathrm{~A}$ & $\mathrm{C}$ & $\mathrm{A}$ & $\mathrm{G}$ & $\mathrm{A}$ & \\
S5 & 1 & $5 \mathrm{~A}$ & $\mathrm{C}$ & $\mathrm{A}$ & $\mathrm{A}$ & $\mathrm{A}$ & \\
S6 & 1 & $6 \mathrm{~A}$ & $\mathrm{U}$ & $\mathrm{A}$ & $\mathrm{G}$ & $\mathrm{A}$ & \\
S7 & 8 & $6 \mathrm{~A}$ & $\mathrm{U}$ & $\mathrm{A}$ & $\mathrm{A}$ & $\mathrm{A}$ & \\
S8 (I2) & 1 & $6 \mathrm{~A}$ & $\mathrm{C}$ & $\mathrm{A}$ & $\mathrm{G}$ & $\mathrm{A}$ & \\
S9 & 3 & $6 \mathrm{~A}$ & $\mathrm{C}$ & $\mathrm{A}$ & $\mathrm{G}$ & $\mathrm{A}$ & $145 \mathrm{G} / \mathrm{A}(\mathrm{V})$ \\
S10 & $7 \mathrm{~A}$ & $\mathrm{C}$ & $\mathrm{A}$ & $\mathrm{G}$ & $\mathrm{A}$ & \\
\hline
\end{tabular}

PSTVd variants used for inoculations (v) and their infectious parental sequences (p)

\begin{tabular}{lllllll}
\hline I2-50 (v) & na & 6 A & C & G & G & A \\
I2 (p) & na & 6 A & C & A & G & A \\
I4-37 (v) & na & 5 A & U & A & G & U \\
I4 (p) & na & 5 A & C & A & G & A \\
\hline
\end{tabular}

The nucleotide changes observed, compared to the non-infectious (I2-50 and I4-37) and viable (I2 and I4) variants are shown. Letters in brackets indicate the viroid domains in which the sites of interest are located: $\mathrm{P}$, pathogenicity, C, central, V, variable, TR, right terminal; na, not applicable. Nucleotide numbers according to Gross et al. (1978).

To further analyze these results the PSTVd clones isolated from transcript inoculated plants were sequenced. Unexpectedly, in the case of I2-50 inoculum all ten analyzed sequences were identical to I2. Similarly only I2 was detected in ten clones isolated from plants co-inoculated with the mixture of I2-50 and I4-37 transcripts. Strikingly, the original I4-37 and I2-50 sequences were not identified among the progeny of the mixed inoculation. The progeny resulting from inoculation with I4-37 transcripts shows considerable variation. Among twenty clones isolated from I4-37 infected plants, eight variants were found, six of them representing novel sequences (Table 2). Once again the original
I4-37 sequence was not found in the progeny. Since no variants present in the original inoculum were recovered in the inoculated plants, one may conclude that both the I2-50 and I4-37 sequences are functionally defective and can be outcompeted in the progeny by other variants.

\section{Sequence analysis of progeny resulting from cDNA inoculations}

Analysis of the sequences obtained revealed five major positions (nucleotides 118, 164, 173, 197 and 310; Table 1) in which nucleotide changes were observed, compared to the original non-infectious I2-50 and I4-37 vari- 
Table 2. PSTVd parental and progeny variants accumulating in tomato 'Rutgers' plants inoculated with the full-length I4-37 transcript.

\begin{tabular}{|c|c|c|c|c|c|c|c|}
\hline \multirow{2}{*}{$\begin{array}{l}\text { Sequence variant found in } \\
\text { the progeny }\end{array}$} & \multirow{2}{*}{$\begin{array}{l}\text { Number of vari- } \\
\text { ants with a given } \\
\text { sequence }\end{array}$} & \multicolumn{6}{|c|}{ Nucleotide position } \\
\hline & & $\begin{array}{l}118 \\
(\mathrm{C} / \mathrm{V})\end{array}$ & $\begin{array}{l}164 \\
(\mathrm{TR})\end{array}$ & $\begin{array}{l}173 \\
(\mathrm{TR})\end{array}$ & $\begin{array}{l}197 \\
(\mathrm{TR})\end{array}$ & $\begin{array}{l}310 \\
(\mathrm{P})\end{array}$ & Other \\
\hline $\mathrm{S}(\mathrm{t}) 1$ & 2 & $5 \mathrm{~A}$ & $\mathrm{U}$ & $\mathrm{A}$ & A & $\mathrm{A}$ & $126 \mathrm{~A} / \mathrm{U} \quad(\mathrm{V})$ \\
\hline $\mathrm{S}(\mathrm{t}) 2$ (I2) & 4 & $6 \mathrm{~A}$ & $\mathrm{C}$ & $\mathrm{A}$ & $\mathrm{G}$ & $\mathrm{A}$ & \\
\hline $\mathrm{S}(\mathrm{t}) 3$ & 1 & $6 \mathrm{~A}$ & $\mathrm{C}$ & $\mathrm{A}$ & $\mathrm{G}$ & $\mathrm{A}$ & $163 \mathrm{C} / \mathrm{G}$ (TR) \\
\hline $\mathrm{S}(\mathrm{t}) 4$ & 1 & $6 \mathrm{~A}$ & $\mathrm{C}$ & $\mathrm{A}$ & $\mathrm{G}$ & - & \\
\hline $\mathrm{S}(\mathrm{t}) 5$ & 2 & $6 \mathrm{~A}$ & $\mathrm{C}$ & $\mathrm{A}$ & $\mathrm{A}$ & $\mathrm{A}$ & \\
\hline $\mathrm{S}(\mathrm{t}) 6$ & 1 & $6 \mathrm{~A}$ & $\mathrm{C}$ & $\mathrm{A}$ & $\mathrm{A}$ & $\mathrm{U}$ & \\
\hline $\mathrm{S}(\mathrm{t}) 7$ (S7) & 4 & $6 \mathrm{~A}$ & $\mathrm{U}$ & $\mathrm{A}$ & $\mathrm{A}$ & $\mathrm{A}$ & \\
\hline $\mathrm{S}(\mathrm{t}) 8$ & 5 & $6 \mathrm{~A}$ & $\mathrm{U}$ & $\mathrm{A}$ & A & $\mathrm{U}$ & \\
\hline \multicolumn{8}{|l|}{$\begin{array}{l}\text { PSTVd variant used for in- } \\
\text { oculations (v) and its infec- } \\
\text { tious parental (p) sequence }\end{array}$} \\
\hline $\mathrm{I} 4-37(\mathrm{v})$ & na & $5 \mathrm{~A}$ & $\mathrm{U}$ & $\mathrm{A}$ & G & $\mathrm{U}$ & \\
\hline I4 (p) & na & $5 \mathrm{~A}$ & $\mathrm{C}$ & $\mathrm{A}$ & $\mathrm{G}$ & $\mathrm{A}$ & \\
\hline
\end{tabular}

The nucleotide changes observed compared to the non-infectious I4-37 and viable I4 variants are shown.

ants. Position 118 (A-stretch overlapping the C and $\mathrm{V}$ domains) is characterized by the presence of a run of 5 or 6 A residues. The length of the A-stretch does not seem to influence the viability of the progeny, since variants carrying 5 or $6 \mathrm{~A}$ are found in almost equal numbers. Moreover, the infectious parental I 2 and I4 sequences carry runs of 6 and $5 \mathrm{~A}$, respectively. The length of the A-stretch is even more variable: the $\mathrm{S} 10$ variant carries a stretch of $7 \mathrm{~A}$.

In position 173 located within TR domain responsible for cell-to cell spread (Hammond, 1994) and $310 \mathrm{P}$ domain responsible for pathogenicity (Schnölzer et al., 1985) of all the progeny sequences analyzed, as well as in the viable parental I2 and I4 sequences (Góra-Sochacka et al., 1997), the only nucleotide observed was A. It is noteworthy that this nucleotide was not present in the corresponding positions of the non-infectious I2-50 and I4-37 PSTVd variants, where 173G and $310 \mathrm{U}$, respectively were present.

I2-50 differs from the parental I2 sequence (Table 1) in an A/G173 substitution located in the
TR domain, while I4-37 differs from the parental I4 sequence in two positions: an A/U310 substitution in the $\mathrm{P}$ domain and a C/U164 substitution in the TR domain. These mutations could impede viroid infectivity. For instance mutations located in the TR domain (positions 164 and 173) may negatively influence transport of the pathogen (Gozmanova et al., 2003; Hammond 1994; Maniataki et al., 2003).

The presence of an A residue in positions 173 and 310 of progeny variants $\mathrm{S} 1$ to $\mathrm{S} 10$ suggests that it is the only acceptable nucleotide at these positions and could be a key factor for maximum viroid propagation. Indeed, in all PSTVd variants cloned in this experiment, these positions are invariably occupied by A. Analysis of the viable progeny of the mixed infection shows clearly that variants with mutations at these positions (173 and 310 ) reverted to the infectious parental 
sequences in all the sequenced clones regardless of other changes in the sequence (Table 1).

In position 164 only two nucleotides ( $\mathrm{C}$ and U) are allowed. This site is located in the upper strand of the molecule (positions 161-169) that is involved with another distant site (positions 128-136, in the V domain) in the formation of a transitory structure designated hairpin III (Hecker et al., 1988). A detailed analysis reveals that within this hairpin, the nucleotide of interest $\mathrm{C} 164$ forms a classical Watson-Crick pair with G133. The other observed nucleotide in position 164 is $\mathrm{U}$ which could form a less stable non-canonical basepair with G (Feng et al., 1993). The presence of any other nucleotide in position 164 would lead to destabilization of the proposed hairpin (Hecker et al., 1988) and indeed was not found.

In canonical rod-like viroid structures, position 164 is also involved in forming a Watson-Crick bond with another site of interest, position 197 in the TR domain (Gross et al., 1978). This interaction is believed to be responsible for maintaining the native secondary rod-like structure of the PSTVd molecule. This issue is further discussed below.

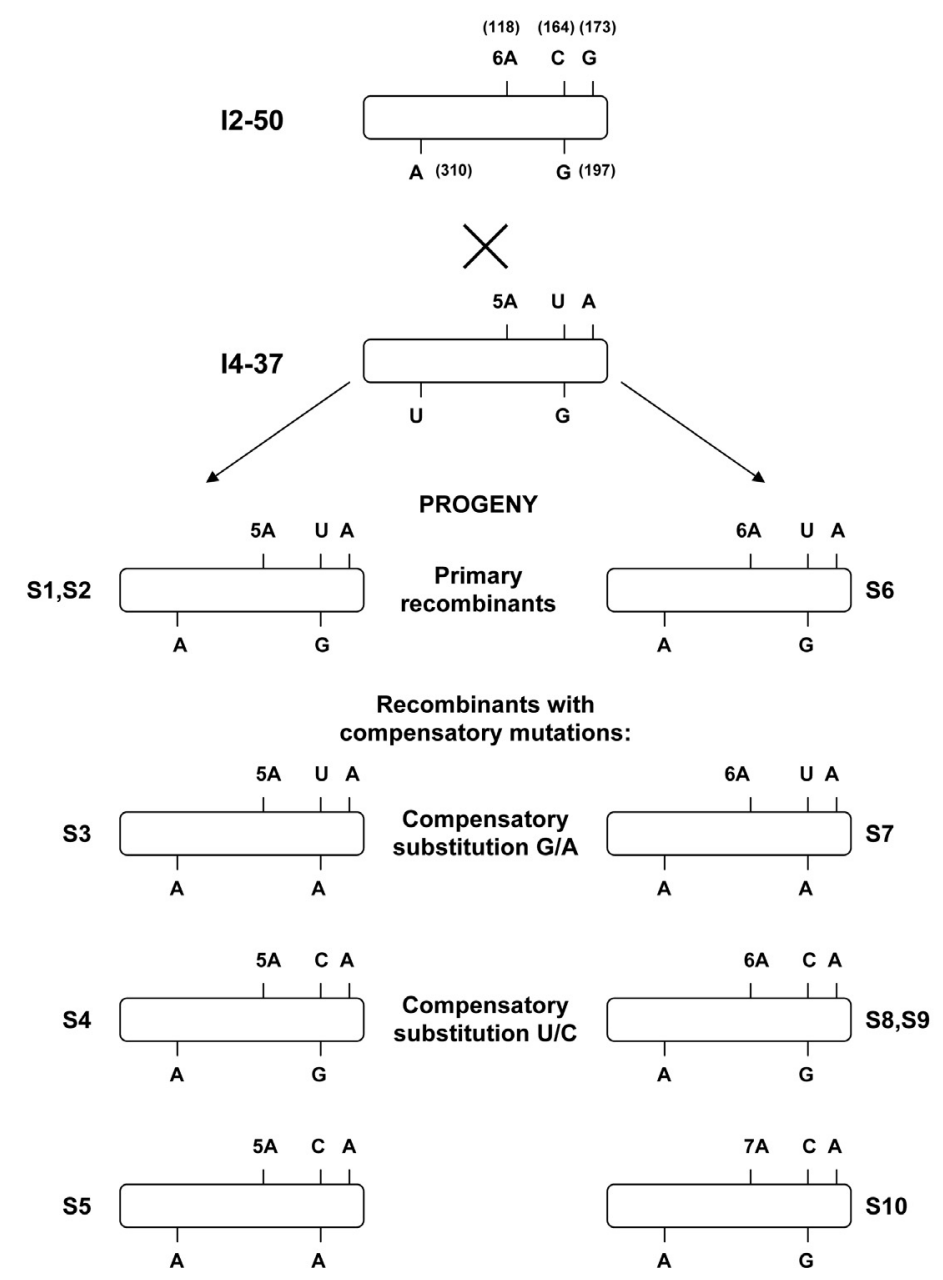

Figure 1. Infectious PSTVd sequence variants detected in tomato plants co-inoculated with the full-length cDNAs (cloned in pUC9) of the non-infectious clones I2-50 and I4-37.

The sites of interest where nucleotide changes have occurred are indicated. The numbers in brackets indicate nucleotide positions. The variants are ordered according to the type of observed nucleotide changes. Variants S1, S2, $\mathrm{S} 6$ can result from direct recombination events between the PSTVd cDNAs. The next variant molecules could be the result of compensatory mutations. The S2 and S9 variants carry additional mutations that are not highlighted here (see Table 1). 


\section{Hypothetical progression of sequences}

Sequence analysis allows one to arrange the studied PSTVd variants in a hypothetical "sequence progression tree" reflecting the sequence relationships between the variants. According to this analysis, mixed infections with cDNAs of the I2-50 and I4-37 genomes could lead to the primary recombinants $\mathrm{S} 1$, S2 or S6 (Fig. 1). Subsequent stepwise point mutations would lead to the creation of a whole spectrum of variants.

\section{Recombination}

The new versions of PSTVd isolated from the plants inoculated with cDNA are very similar to both the I2-50 and I4-37 inocula. A thorough analysis of the progeny sequences and the circumstances in which they appeared suggest that these novel sequences capable of spreading result from recombination
(Allison et al., 1990; Keese \& Symons, 1985) and subsequent compensatory mutations. This interpretation is supported by the observation that only co-inoculation with $\mathrm{cDNA}$ of both non-infectious clones leads to infection and appearance of viable PSTVd variants, whereas separate inoculations do not. Therefore it seems reasonable to propose that recombination restored within the progeny some of the functions lost in the non-infectious variants (Kofalvi et al., 1997; Owens et al., 1998; Rezaian, 1990; White \& Morris, 1994). Indeed, the novel recombinant PSTVd variants seem to be fully competent in replication and transport.

The very nature and choice of the PSTVd clones used in the experiments can explain the biology of the recombinants. Each variant (I2-50 or I4-37) contained specific elements that could replace defective elements in the counterpart molecule. As observed here, recombination becomes a rescue mechanism by

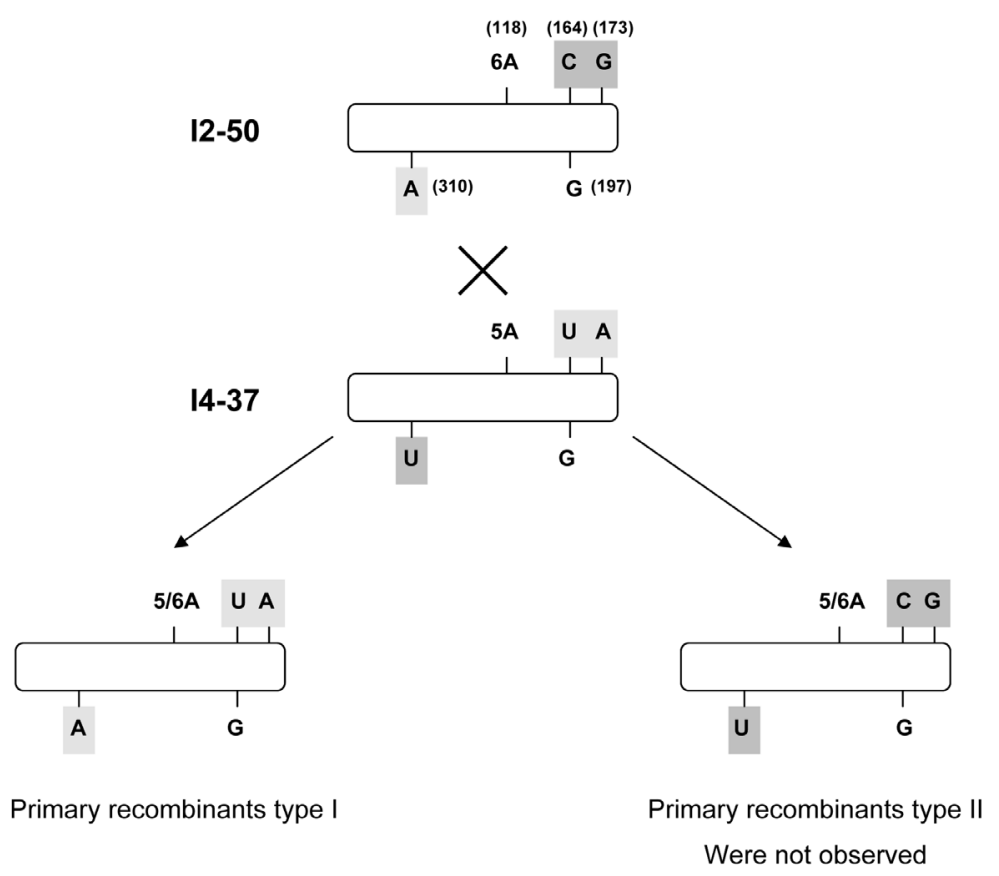

Figure 2. Hypothetical recombination events between the non-infectious I2-50 and I4-37 PSTVd molecules giving rise to primary recombinants.

Primary recombinants type I re-create a population of fully infectious variants via a series of compensatory mutations. Primary recombinants type II were not found in the population of molecules identified in the co-infection experiment when a mixture of both full-length cDNAs (cloned in pUC9) was used as inoculum; hence they are probably non-viable. The numbers in brackets indicate nucleotide positions where changes are observed. Shading of nucleotides indicates directions of nucleotide exchange during recombination events. 
which defective parts of the genome can be eliminated leading to the appearance of new viable entities (Lai, 1992; Carpenter \& Simon, 1996; Nagy \& Simon, 1997; Worobey \& Holmes, 1999). Subsequent compensatory mutations can lead to the appearance of the parental variants I 2 and I4, since among the cDNAs sequenced the I2 (sequence variant S8, 1 out of 30 sequences; 1/30) and I4 (sequence variant $\mathrm{S} 4,7 / 30$ ) sequences were also found.

\section{Model of recombination}

The primary recombination event is apparently asymmetric. Taking into account the marker positions in the I2-50 and I4-37 genomes one can propose a model for the emergence of recombinant molecules (Fig. 2). In agreement with this model, only recombinants incorporating A310 from I2-50, and U164 and A173 from I4-37 were detected (primary recombinants type I). An alternative recombination event incorporating other nucleotides, C164 and G173 of I2-50, and U310 of I4-37 would lead to primary recombinants type II, but they were not detected in the progeny (Fig. 2) and have never been found in the entire collection of viable variants described in the literature (Genebank data). Taking into account the conservation of $\mathrm{A}$ in positions 173 and 310 , the apparent asymmetry of recombination seems to result from selection against recombinants of type II.

The presence of stretches of 6 or $5 \mathrm{~A}$ in the progeny cannot be easily explained in terms of recombination. However, an A residue could be either added or lost during replication since the length of $\mathrm{A}$ runs tends to be variable.

Although the first products of recombination $\mathrm{S} 1, \mathrm{~S} 2$ and $\mathrm{S} 6$ carry the wobble pair $\mathrm{U}: \mathrm{G}$ (between positions 164 and 197), the overwhelming majority of variants carry the canonical U:A (13/30 sequences: S3, S7) or C:G (12/30 sequences: S4, S8, S9) pair (Table 1). This tendency indicates that proper pairing at these positions is probably restored by compensatory mutations and is important to maintain the native rod-like structure of the pathogen. An unfavorable structure can also explain the low frequency ( $1 / 30$ sequences) of occurrence of the S5 variant (Table 1) carrying the mismatched base pair C:A.

It is quite likely that the novel infectious molecules have originated during recombination at the level of cDNA. Events of homologous recombination between foreign DNA molecules in plant cells have been observed and described previously (Baur et al., 1990; De Groot et al., 1992; Lyznik et al., 1991; Puchta \& Hohn, 1991). We propose that an analogous event could occur between the PSTVd inserts carried by plasmid pUC9 molecules. They exhibit such a high homology that under proper conditions the recombination could easily occur. Alternatively the recombinants could originate during transcription due to a copy-choice mechanism (Aziz \& Tepfer, 1999). However, recombination was not observed in the transcript experiments in which, unexpectedly, co-inoculation led to the appearance of only one variant, I2. This along with the proven infectivity of the inocula prepared by in vitro transcription of appropriate cDNAs could be explained by heterogeneity of the transcripts. Transcription by SP6 polymerase is prone to errors $\left(1.34 \times 10^{-4}\right.$ per copied nucleotide) and can lead to several mutations (Pugachev et al., 2004). It is quite likely that in the I2-50 and mixed (I2-50 and I4-37) inocula, the I2 transcript has already been present as a result of a transcription error. Its sequence only differs by one nucleotide in position 173 from the original I2-50 variant and once in the cell it might rapidly replicate and spread overriding any other less infectious PSTVd variants. The high infectivity and efficiency of $\mathrm{I} 2$ replication could be the reason why within the progeny of mixed inoculations only this variant is found. A similar transcription error could create viable mutants in the I4-37 inoculum. 


\section{Comparison with NCBI database}

An analysis of 76 sequences (Table 3) retrieved from the NCBI database supports our findings. The most striking observation is the presence of $\mathrm{A}$ in position 173 in all the sequences analyzed, which is in agreement with
Canonical pairing involving position 164 also seems to be preferred (6/10), but not in all cases $(4 / 10)$. The overwhelming number of molecules carrying correctly paired nucleotides reflects the importance of a stable secondary structure for the life cycle of PSTVd (Wassenegger et al., 1994).

Table 3. Summary of PSTVd sequences retrieved from the NCBI database

\begin{tabular}{|c|c|c|c|c|c|}
\hline \multirow{2}{*}{$\begin{array}{l}\text { Number of similar sequences re- } \\
\text { trieved from the NCBI database }\end{array}$} & \multicolumn{5}{|c|}{ Nucleotide position } \\
\hline & $\begin{array}{l}118 \\
(\mathrm{C} / \mathrm{V})\end{array}$ & $\begin{array}{l}164 \\
(\mathrm{TR})\end{array}$ & $\begin{array}{l}173 \\
(\mathrm{TR})\end{array}$ & $\begin{array}{l}197 \\
(\mathrm{TR})\end{array}$ & $\begin{array}{l}310 \\
(\mathrm{P})\end{array}$ \\
\hline 4 & $5 \mathrm{~A}$ & $\mathrm{C}$ & $\mathrm{A}$ & $\mathrm{G}$ & A \\
\hline 47 & $6 \mathrm{~A}$ & $\mathrm{C}$ & $\mathrm{A}$ & G & A \\
\hline 2 & $5 \mathrm{~A}$ & $\mathrm{C}$ & $\mathrm{A}$ & G & $\mathrm{U}$ \\
\hline 2 & $6 \mathrm{~A}$ & $\mathrm{C}$ & $\mathrm{A}$ & G & $\mathrm{U}$ \\
\hline 11 & AAUAA & $\mathrm{C}$ & $\mathrm{A}$ & G & $\mathrm{C}$ \\
\hline 1 & AAUAA & $\mathrm{C}$ & $\mathrm{A}$ & G & G \\
\hline 1 & AAUAA & $\mathrm{C}$ & $\mathrm{A}$ & G & A \\
\hline 3 & AAUAA & $\mathrm{C}$ & $\mathrm{A}$ & G & $\mathrm{U}$ \\
\hline 1 & AAUAA & $\mathrm{C}$ & A & G & - \\
\hline 1 & AAUA & $\mathrm{C}$ & A & G & $\mathrm{U}$ \\
\hline 2 & AAAAG & $\mathrm{U}$ & A & A & G \\
\hline 1 & AAAAG & $\mathrm{U}$ & A & G & G \\
\hline
\end{tabular}

Seventy-six sequences retrieved from the database were analyzed and categorized according to identity at selected sites of interest with the sequences recovered in the present experiment. Numbers in the first column indicate the number of sequences carrying identical combinations of nucleotides in the sites of interest.

the sequences presented here. It becomes clear that $\mathrm{G}$ in this position in I2-50 could have a negative effect on the infectivity of the molecule (Maniataki et al., 2003). Other similarities can also be drawn. Position 164 is occupied primarily by $\mathrm{C}(73 / 76)$ and rarely by $\mathrm{U}$ (3/76) and position 197 by $G(74 / 76)$ and rarely by $A(2 / 76)$. In the proposed native rod-like secondary structure of PSTVd, the canonical C:G and U:A pairs between these two positions are observed. The sequences identified in the present report also carry $\mathrm{C}$ or $\mathrm{U}$ at position 164 but in equal proportions (Table 1). Position 197 is occupied mostly by $\mathrm{G}$ (7/10 variants), but $A$ is also found $(3 / 10)$.

\section{CLOSING REMARKS}

Taking into account the sequence analysis of the progeny recovered from the experiments in which cDNA was used, we suggest that non-infectious mutants are possibly impeded in cell-to-cell transport but are able to replicate at the site of infection. We also propose that the PSTVd progeny observed in this experiment arose by recombination - a process that restored in the progeny some of the functions lost in the non-infectious variants (Kofalvi et al., 1997; Owens et al., 1998; Rezaian, 1990; White \& Morris, 1994). Indeed, novel recombinant PSTVd variants seem to be fully compe- 
tent in replication and transport. Both PSTVd variants used in the experiment carry mutations (A/G in I2-50 and C/U in I4-37) in the TR domain, a region of the PSTVd genome known to be responsible for viroid transport in plants (Hammond, 1994). We suggest that such mutations prevent those variants from spreading throughout the host.

At the same time we observed that inoculations even with separate transcripts of the non-infectious variants could induce infection. The lack of the original I2-50 and I4-37 sequences within the progeny along with the appearance of novel repaired variants in single transcript inoculations prompts us to propose that the infectious progeny derives from chance mutations during in vitro SP6 transcription rather than from their repair in vivo. Since transcripts are naturally heterogeneous, viable, repaired PSTVd molecules like I2, could already be present in the inoculum. The original I2-50 and I4-37 sequences are truly non-infectious regardless of the type of inoculum. They cannot be found in the progeny even when delivered into the plant in the form of full-length transcripts.

The potential transcript heterogeneity leads to the conclusion that they should not be used for experiments when the fate of a specific sequence is to be investigated. Therefore, cDNA inoculations used routinely to assess the properties of specific variants represent the best way to evaluate their properties. This very precise tool allows introduction into a host plant of a single variant of specified sequence and to follow its fate during symptom development.

We would like to thank Anne-Lise Haenni for critical reading and helpful suggestions regarding the manuscript.

\section{R E F E R E N C E S}

Allison R, Thompson G, Ahlquist P. (1990) Regeneration of a functional RNA virus ge- nome by recombination between deletion mutants and requirement for cowpea chlorotic mottle virus $3 \mathrm{a}$ and coat genes for systemic infection. Proc Natl Acad Sci USA.; 87: $1820-4$.

Aziz R, Tepfer M. (1999) Recombination in RNA viruses and in virus-resistant transgenic plants. J Gen Virol.; 80: 1339-46.

Baur M, Potrykus I, Paszkowski J. (1990) Intermolecular homologous recombination in plants. Mol Cell Biol.; 10: 492-500.

Candresse T, Diener TO, Owens RA. (1990) The role of the viroid central conserved region in cDNA infectivity. Virology.; 175: 232-7.

Carpenter CD, Simon AE. (1996) Changes in locations of crossover sites over time in de novo generated RNA recombinants. Virology.; 223: 165-73.

De Groot MJA, Offringa R, Does MP, Hooykaas PJJ, Van den Elzen JM. (1992) Mechanisms of intermolecular homologous recombination in plants as studied with single- and double-stranded DNA molecules. Nucleic Acids Res.; 20: 2785-94.

Diener TO. (1971) Potato spindle "virus". A replicating, low molecular weight RNA. Virology.; 45: 411-28.

Feng Q, Heinrich C, Loss P, Steger G, Po T, Riesner D. (1993) Multiple pathways of reversion in viroids for conservation of structural elements. EMBO J.; 12: 2129-39.

Fernow KH. (1967) Tomato test plant for detecting mild strains of potato spindle tuber virus. Phytopathology.; 57: 1347-52.

Gandia M, Duran-Vila N. (2004) Variability of the progeny of a sequence variant Citrus bent leaf viroid (CBLVd). Arch Virol.; 149: 407-16.

Gozmanova M, Denti MA, Minkov IN, Tsagaris M, Tabler M. (2003) Characterization of RNA motif responsible for the specific interaction of potato spindle tuber viroid RNA (PSTVd) and tomato protein Virp1. Nucleic Acids Res.; 31: 5534-43. 
Gomez J, Martell M, Quer J, Cabot B, Esteban JI. (1999) Hepatitis C viral quasispecies. $J$ Viral Hepat.; 6: 3-16.

Góra A, Candressse T, Zagórski W. (1994) Analysis of the population structure of three phenotypically different PSTVd isolates. Arch Virol.; 138: 233-45.

Góra-Sochacka A, Kierzek A, Candresse T, Zagórski W. (1997) The genetic stability of potato spindle tuber viroid (PSTVd) molecular variants. $R N A$.; 3: 68-74.

Gross HJ, Lossow C, Jank P, Raba M, Alberty H, Sänger HL. (1978) Nucleotide sequence and secondary structure of potato spindle tuber viroid. Nature.; 273: 203-8.

Hammond RW. (1994) Agrobacterium-mediated inoculation of PSTVd cDNAs onto tomato reveals the biological effects of apparently lethal mutations. Virology.; 201: 36-45.

Hecker R, Wang Z, Steger G, Riesner D. (1988) Analysis of RNA structures by temperature gradient gel electrophoresis: viroid replication and processing. Gene.; 72: 59-74.

Keese P, Symons R. (1985) Domains in viroids evidence for intermolecular RNA rearrangements and their contribution to viroid evolution. Proc Natl Acad Sci USA.; 82: 4582-6.

Kofalvi S, Marcos J, Canizares M, Pallas V, Candresse T. (1997) Hop stunt viroid (HSVd) sequence variants from Prunus species: evidence for recombination between HSVd isolates. J Gen Virol.; 78: 3177-86.

Lai M. (1992) RNA Recombination in animal and plant viruses. Microbiol Rev.; 56: 61-79.

Lyznik LA, McGee JD, Tung PY, Bennetzen JL, Hodges TK. (1991) Homologous recombination between plasmid DNA molecules in maize protoplasts. Mol Gen Genet.; 230: 209-18.

Maniataki E, Martinez de Alba AE, Gesser RS, Tabler M, Tsagris M. (2003) Viroid RNA systemic spread may depend on the interaction of a 71-nucleotide bulged hairpin with the host protein VirP1. RNA.; 9: 346-54.
Nagy P, Simon A. (1997) New insights into mechanisms of RNA recombination. Virology.; 235: 1-9.

Naraghi-Arani P, Daubert S, Rowhani A. (2001) Quasispecies nature of the genome of grapewine fanleaf virus. $J$ Gen Virol.; 82: 1791-5.

Owens RA, Yang G, Gundersen-Rindal D, Hammond RW, Candresse T, Bar-Joseph M. (2000) Both point mutation and RNA recombination contribute to the sequence diversity of citrus viroid III. Virus Genes.; 20: $243-52$.

Pellerin M, Lopez-Aguirre Y, Penin F, Dhumeaux D, Pawlotsky JM. (2004) Hepatitis $\mathrm{C}$ virus quasispecies variability modulates nonstructural protein 5A transcriptional activation, pointing to cellular compartmentalization of virus-host interactions. J Virol.; 78: 4617-27.

Puchta H, Hohn B. (1991) A transient assay in plant cells reveals a positive correlation between extrachromosomal recombination rates and length of homologous overlap. $\mathrm{Nu}$ cleic Acids Res.; 19: 2693-700.

Pugachev KV, Guirakhoo F, Ocran SW, Mitchell F, Parsons M, Penal C, Girakhoo S, Pougatcheva SO. Arroyo J, Trent DW, Monath TP. (2004) High fidelity of yellow fever virus RNA polymerase. $J$ Virol.; 78: 1032-8.

Rezaian M. (1990) Australian grapevine viroid - evidence for extensive recombination between viroids. Nucleic Acids Res.; 18: 1813 $-8$.

Schneider WL, Roossinck MJ. (2001) Genetic diversity in RNA virus quasispecies is controlled by host-virus interactions. $J$ Virol.; 75: $6566-71$.

Schnölzer M, Hass B, Ramm K, Hofmann H, Sanger HL. (1985) Correlation between structure and pathogenicity of potato spindle tuber viroid (PSTVd). EMBO J., 4: 2181-90

Wassenegger M, Heimes S, Sänger HL. (1994) An infectious viroid RNA replicon evolved from an in vitro generated non-infectious 
viroid deletion mutant via a complementary deletion in vivo. EMBO J.; 13: 6172-7.

Wełnicki M, Hiruki C. (1993) Chemiluminescent assay for the detection of viral and viroid RNAs using digoxygenin-labeled probes. In Bioluminescence and Chemiluminescence Status Report. Szalay AA, Stanley PE, Kricka LJ. eds, pp 415-19. John Wiley, Chichester.
White K, Morris T. (1994) Recombination between defective tombusvirus RNAs generates functional hybrid genomes. Proc Natl Acad Sci USA.; 91: 3642-6.

Worobey M, Holmes EC. (1999) Evolutionary aspects of recombination in RNA viruses. $J$ Gen Virol.; 80: 2535-43. 